\title{
Shadow analysis of buildings over urban express way by using three-dimensional GIS - To study the distribution of long remained snow cover that made express way close for five days
}

\author{
Daichi Shiroki $^{\mathrm{a}}$ and Hiroshi Masaharu ${ }^{\mathrm{a}, *}$ \\ ${ }^{a}$ Toyo University, Department of Civil and Environmental Engineering, masaharu@toyo.jp \\ * Corresponding author
}

Keywords: 3-D GIS, building shadows, photogrammetry

\section{Abstract:}

In January 2018, it snowed heavily in Kanto area including Tokyo Metropolitan Area, Japan. Due to the snowfall, many cars stuck on the Metropolitan Express Way for about ten hours and the express way was closed for five days. There are many conditions that affect melting snow cover such as temperature, wind and weather. Among them, we paid attention to the shadows casted on the express way from high buildings surrounding the road. Insolation can be calculated if the three dimensional shapes of buildings and the road by using functions of three-dimensional GIS. This information of insolation of time and date are one of the conditions that affect the speed of snow melting and it can be used for preparing countermeasures against heavy snow fall.

We chose area near Kandabashi-junction of Metropolitan Express way where maximum gradient of slopes was nine per cent and had severe traffic condition in snow fall. Procedures of the data preparation and analysis are as follows.

Polygon data of buildings and road edge data were obtained by downloading the Fundamental Geographic Data provided by the Geospatial Information Authority of Japan. But these data have no height information. Therefore we carried out three dimensional measurement using photogrammetry. Aerial photos of $0.22 \mathrm{~m}$ GSD (ground sample distance) were used for generating 3-D point cloud by using SfM (structure from motion) software PhotoScan professional edition. In total five photos of one course were used to generate DSM (digital surface model). The point cloud and the derived DSM were used for determining the building and road surface height. With these data we developed three-dimensional city model of the target area. Figure 1 shows the 3 -D model made from the aerial photos.

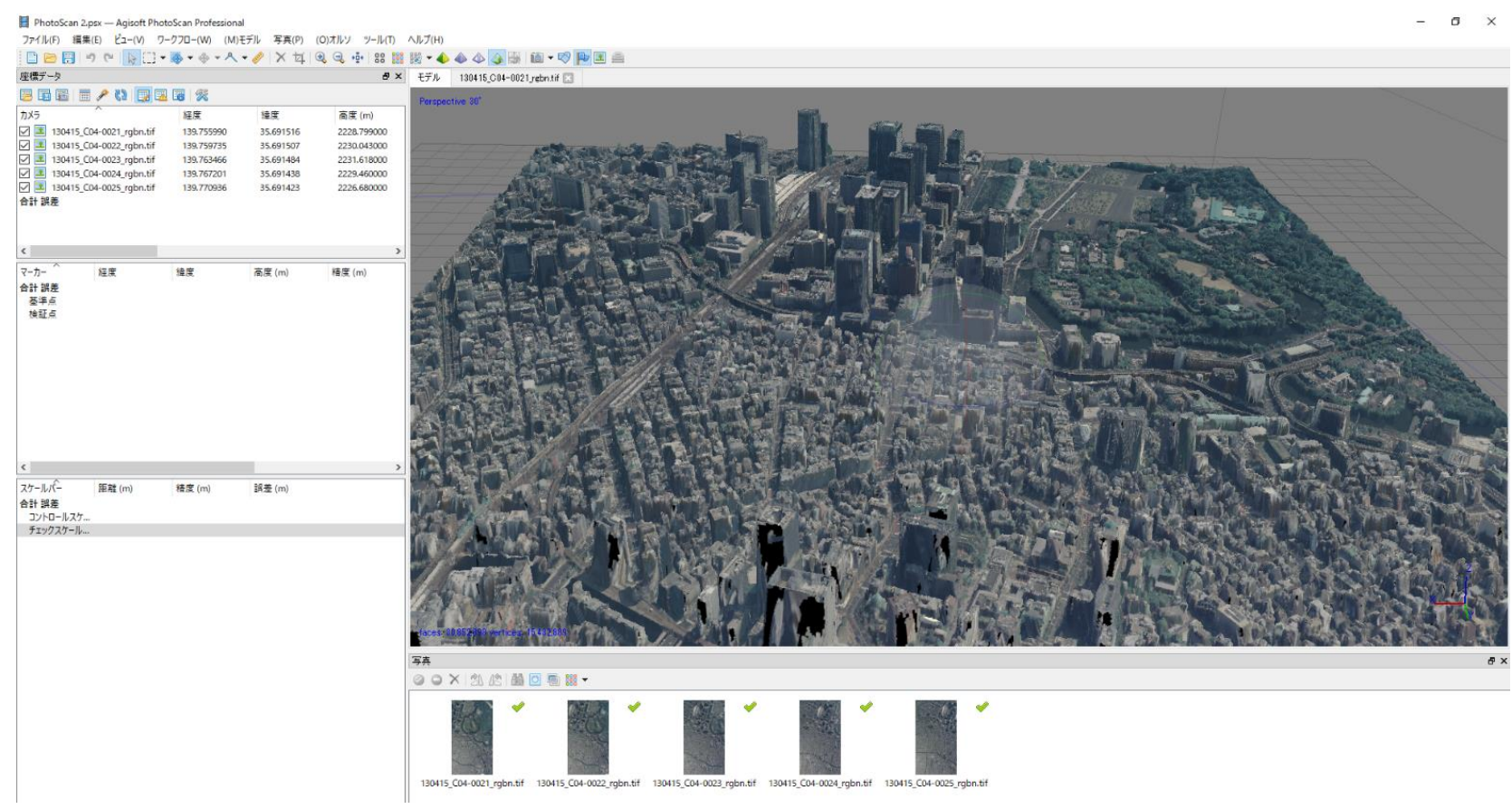

Figure 1. Three dimensional city model including the target area made by the SfM software with the aerial photos 
We used ArcGIS with Spatial Analyst extension for insolation analysis. The tool "Area Solar Radiation" was used to obtain the amount of solar radiation of specified date and time interval. One of the results is shown as Figure 2 . The figure shows solar radiation of direct and scattered rays between January 24 and 25, 2018. It snowed on January 22, but it was fine from January 23 to 25 in Tokyo. Therefore we can see shaded area in this figure that prevented snow melting. Preparing these kind of maps beforehand will help initial operation planning for snow ploughing.

The "Area Solar Radiation" tool can also generate solar radiation map of specified time interval. Figure 3 shows the solar radiation at 12:00 - 13:00 on January 24, 2018. We can identify shaded areas on the express way around noon.

Although we do not have enough detailed data of snow cover depth distribution on the express way at this snow hazard, we consider this areal solar radiation data are useful for managers of the express way to prepare countermeasures against heavy snow fall. This analysis is one of the applications of three-dimensional GIS and city models generated by a photogrammetric method.

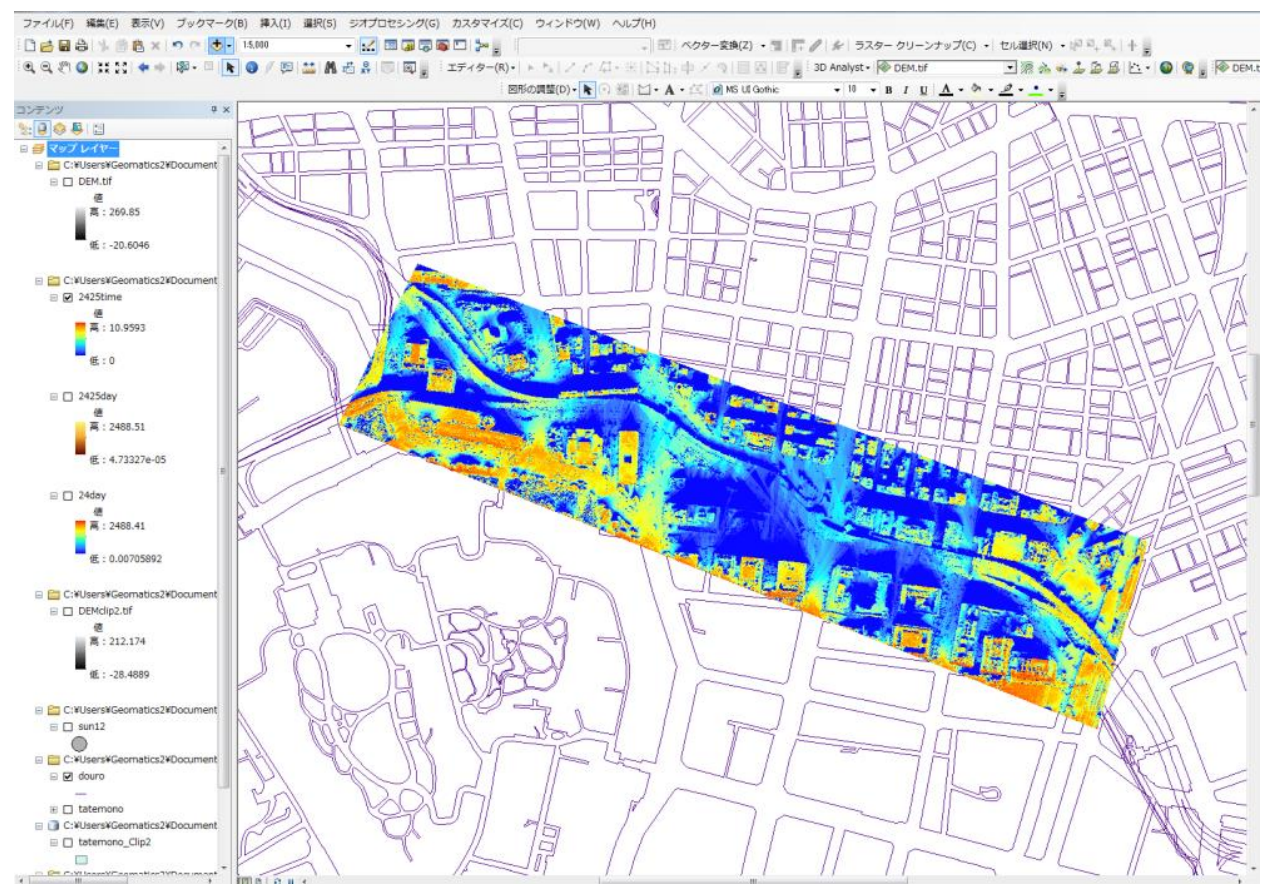

Figure 2. Area solar radiation near Kandabashi-junction on January 24 and 25, 2018 calculated by ArcGIS

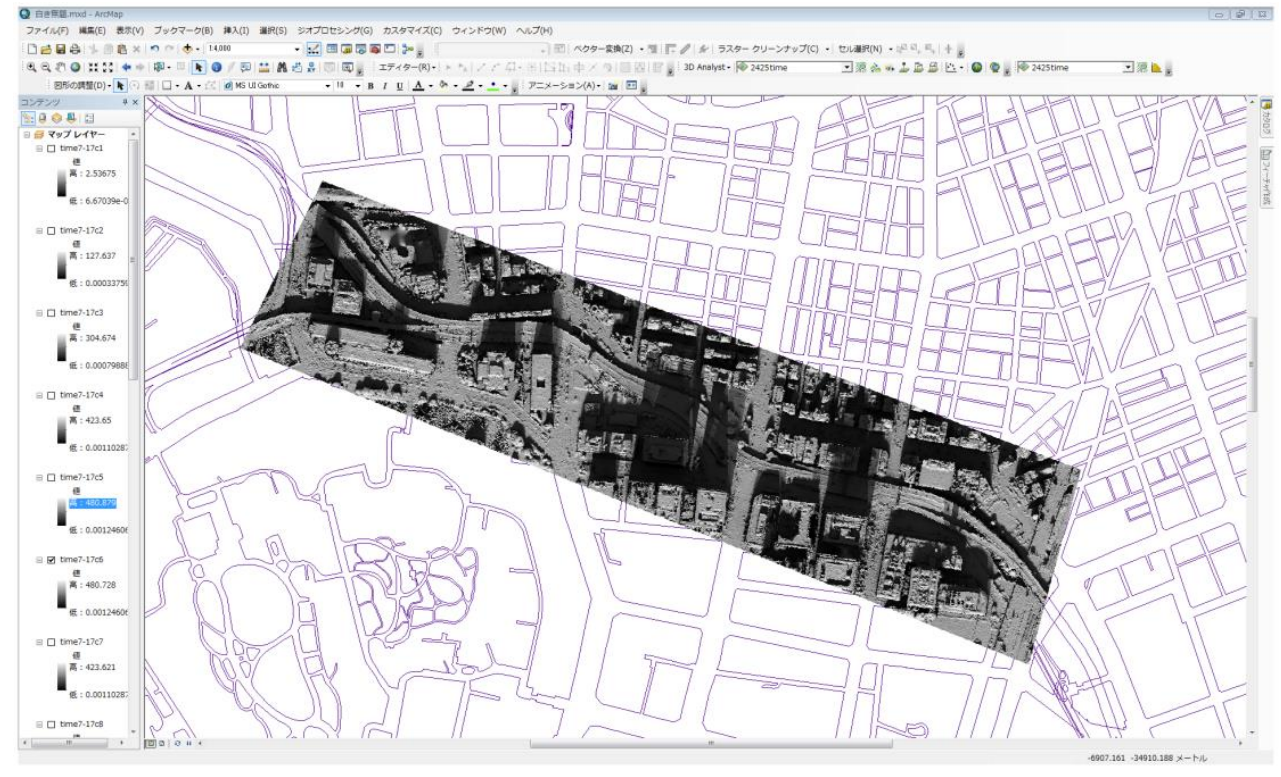

Figure 3. Solar radiation at 12:00 - 13:00, January 24, 2018 